\title{
Mesh fixation to fascia during incisional hernia repair results in increased prevalence of pain at long-term follow up: a multicenter propensity score matched prospective observational study
}

\author{
Andreas Kohler ${ }^{1} \cdot$ Joël L. Lavanchy ${ }^{1} \cdot$ Rahel Gasser $^{1} \cdot$ Roland Wyss $^{2} \cdot$ Lars Nowak $^{3} \cdot$ Andreas Scheiwiller $^{4}$. \\ Peter Hämmerli ${ }^{5}$. Daniel Candinas ${ }^{1} \cdot$ Guido Beldi $^{1}$ D
}

Received: 5 October 2020 / Accepted: 3 February 2021 / Published online: 23 February 2021

(c) The Author(s) 2021

\begin{abstract}
Background Patient-reported outcomes such as postoperative pain are critical for the evaluation of outcomes after incisional hernia repair. The aim of this study is to determine the long-term impact of mesh fixation on postoperative pain in patients operated by open and laparoscopic technique.

Methods A multicenter prospective observational cohort study was conducted from September 2011 until March 2016 in nine hospitals across Switzerland. Patients undergoing elective incisional hernia repair were included in this study and stratified by either laparoscopic or open surgical technique. Propensity score matching was applied to balance the differences in baseline characteristics between the treatment groups. Clinical follow-up was conducted 3, 12 and 36 months postoperatively to detect hernia recurrence, postoperative pain and complications.

Results Three-hundred-sixty-one patients were included into the study. No significant differences in hernia recurrence and pain at 3, 12 and 36 months postoperatively were observed when comparing the laparoscopic with the open treatment group. Mesh fixation by sutures to fascia versus other mesh fixation led to significantly more pain at 36 months postoperatively (32.8\% vs $15.7 \%, p=0.025)$.

Conclusions At long-term follow-up, no difference in pain was identified between open and laparoscopic incisional hernia repair. Mesh fixation by sutures to fascia was identified to be associated with increased pain 36 months after surgery. Omitting mesh fixation by sutures to the fascia may reduce long-term postoperative pain after hernia repair.
\end{abstract}

Keywords Incisional hernia $\cdot$ Mesh fixation $\cdot$ Pain $\cdot$ Long-term follow up $\cdot$ Multicenter study $\cdot$ Propensity score matching

Andreas Kohler and Joël L. Lavanchy have contributed equally to this work.

\section{Guido Beldi}

guido.beldi@insel.ch

1 Department of Visceral Surgery and Medicine, Inselspital, Bern University Hospital, University of Bern, Bern, Switzerland

2 Department of Visceral and Thoracic Surgery, Kantonsspital Winterthur, Winterthur, Switzerland

3 Department of Surgery, Spital Grabs, Grabs, Switzerland

4 Department of General and Visceral Surgery, Kantonsspital Luzern, Luzern, Switzerland

5 Department of Surgery, Spital Walenstadt, Walenstadt, Switzerland
With an incidence of up to $25 \%$, incisional hernia is a frequent long-term complication of open abdominal surgery [1, 2]. Treatment of incisional hernia and related complications induces considerable health-care spending [3, 4].

International guidelines equivocally advocate for an incisional hernia repair with a non-absorbable mesh, because recurrence is two-fold reduced compared to suture repair [5, 6]. Laparoscopic operation technique was shown to reduce postoperative surgical site infections (SSI), overall complications and hospital length of stay. However, recurrence rates do not differ when comparing open and laparoscopic operation technique [7-9].

Long-term patient-reported outcomes remain to be studied in detail to refine surgical techniques [10]. With up to $50 \%$ of patients that underwent incisional hernia repair reporting pain at 6 months follow-up this remains a substantial problem $[11,12]$. Further, the ideal mesh position 
(onlay vs. sublay vs. intraperitoneal) and fixation technique has broadly been discussed in the literature with regard to recurrence of incisional hernia [13-15]. However, these studies often neglect patient-reported outcomes.

We hypothesized that type of mesh fixation technique using tacks, suture fixation to the fascia or the peritoneum is of major importance for the development of chronic pain and might be more important than the actual mesh position.

Therefore, we aimed to report long-term outcomes of the applied surgical techniques, mesh position and fixation technique and assess their relationship with the occurrence of long-term pain.

\section{Material and methods}

\section{Study design}

A prospective observational study including patients that underwent open or laparoscopic incisional hernia repair was conducted in nine hospitals across Switzerland. Patients were included from September 2010 to March 2016, inclusion criteria were age $\geq 18$ years and written informed consent. Exclusion criteria comprised emergency surgery and local or systemic infection at the time of surgery. The primary outcome was recurrence at 3 years after surgery. Secondary endpoints included pain scores on a visual analogue scale (VAS, range 0-10), localization of pain, consumption of pain killers, SSI graded according to the definition of the Center for Disease Control [16] and overall complication graded according to Dindo-Clavien [17].

\section{Data collection}

Following parameters were meticulously recorded during surgery: surgical access (laparoscopic vs. open), mesh material (Polypropylene vs. Polyester vs. other), mesh position (onlay vs. sublay vs. intraperitoneal) and mesh fixation (suture to the facia, suture to the peritoneum and tacks).

Follow-up data were collected during patient visits in the outpatient clinic 3, 12 and 36 months after surgery. Patients completed a standardized questionnaire and a clinical examination of the abdominal wall was performed. If there was a doubt regarding hernia recurrence, imaging studies were ordered.

\section{Statistical analysis}

Categorical variables are reported as numbers and percentages, continuous variables as median and interquartile range (IQR). Statistical differences were analyzed using Fisher's exact test and Mann-Whitney- $U$ test, respectively. A $p$-value $\leq 0.05$ was considered statistically significant.
Propensity score matching was performed by matching for age, sex, body-mass-index (BMI), American Society of Anesthesiologists (ASA) score, hernia size and site of primary incision. Propensity score matching was applied using the MatchIt package for $R$ [18] and Euler diagrams were plotted using the eulerr package for $R$ [19]. All other statistical analyses were performed using SPSS Version 25 (IBM, Armonk, NY).

\section{Results}

During the 66 months study period, 361 patients with a median age of 64.0 (IQR 55.0-71.0) years and a median BMI of $28.7(25.4-33.0) \mathrm{kg} / \mathrm{m}^{2}$ were enrolled. Thereof, 154 (42.7\%) patients underwent laparoscopic and 207 (57.3\%) patients open incisional hernia repair. The detailed flowchart of the study is displayed in Fig. 1. Baseline characteristics of the study groups differed significantly in hernia size and site of primary incision. After propensity score matching no significant differences between the laparoscopic and the open group were left (Table 1).

The operative technique differed significantly between the two study groups (Table 2). In the laparoscopic group more polyester meshes were used $(28.8 \%$ vs. $12.0 \%, p<0.001)$, the mesh position was more frequently intraperitoneal (98.0\% vs. $26.7 \%, p<0.001)$ and tacks were more often used to fix the mesh $(87.3 \%$ vs. $11.3 \%, p<0.001)$ compared to the open group. Operation time was significantly shorter in the laparoscopic group (106 vs. $140 \mathrm{~min}, p<0.001$ ). Figure 2 shows the mesh fixation techniques for the two groups. While mesh fixation by sutures to the fascia was predominantly used in open operated cases, a combination of sutures to the fascia and tack fixation was used in most laparoscopic procedures.

During hospital stay, overall postoperative complications $(9.3 \%$ vs. $21.3 \%, p=0.006)$ and superficial SSI $(0.7 \%$ vs. $5.3 \%, p=0.036$ ) were less frequent in the laparoscopic group compared to the open group (Table 3). Patients who underwent laparoscopic incisional hernia repair showed reduced median hospital length of stay ( 4 vs. 5 days, $p<0.001$ ) compared to patients that underwent open incisional hernia repair.

During the whole study period, there were no significant differences in hernia recurrence between laparoscopic and open incisional hernia repair. Frequency of hernia recurrence was not influenced by mesh fixation technique. Superficial SSI were less frequent in the laparoscopic group compared to the open group at three months postoperatively ( $4.4 \%$ vs. $14.8 \%, p=0.004)$.

The prevalence of patients experiencing pain was similar between the open and laparoscopic group at 3,12 and 36 months after surgery. In those patients experiencing 


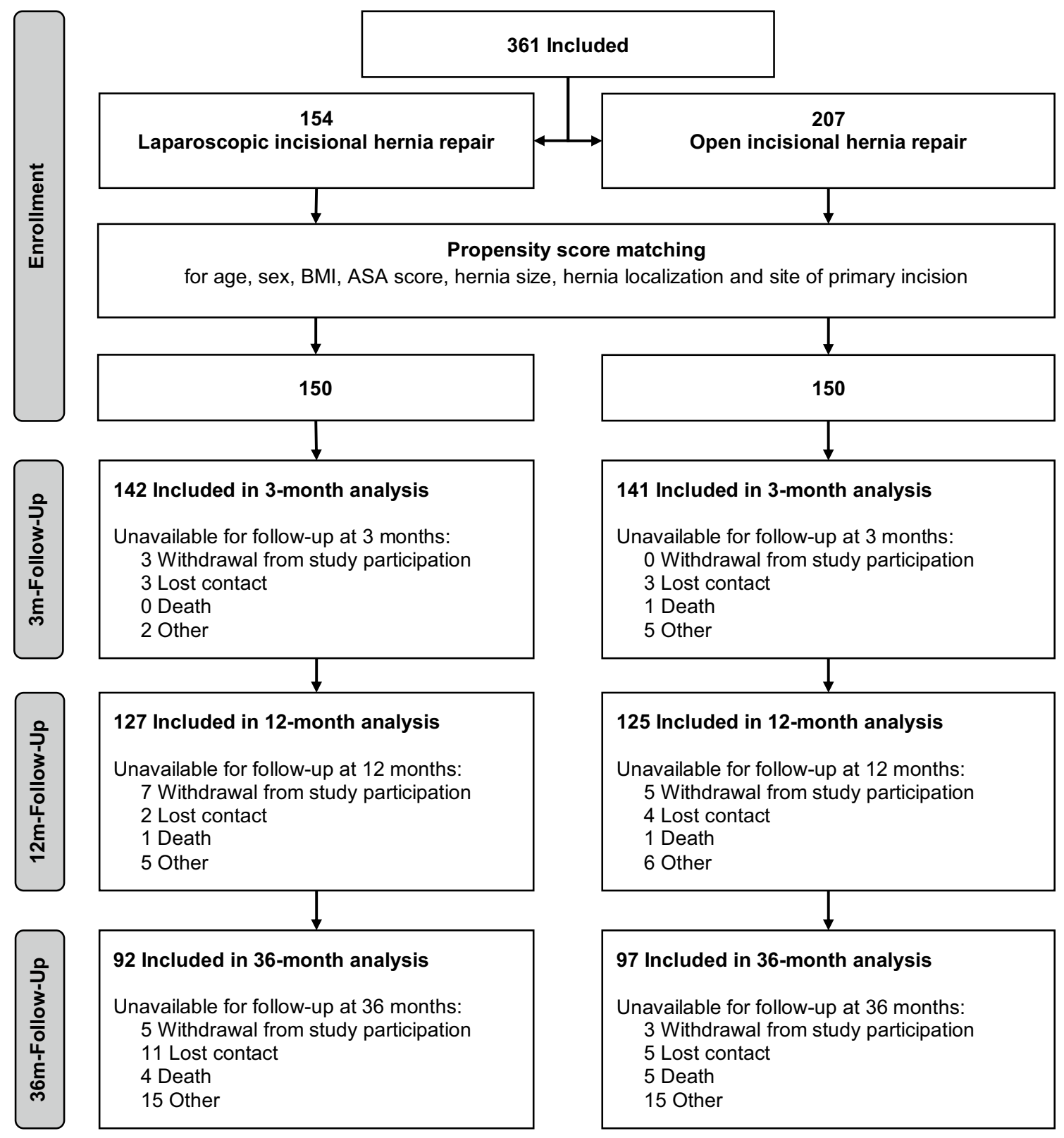

Fig. 1 Patient flow-chart

pain, median pain level was significantly higher (3.5 vs. 2.0 VAS, $p=0.045) 12$ months postoperatively in patients who underwent laparoscopic hernia repair. A similar trend was observed at 36 months after surgery.

During the whole study period, the mesh position had no significant impact on the frequency of pain. However, the mesh fixation technique was of major importance. At 36 months after surgery, significantly more patients with mesh fixation by sutures to the fascia were in pain compared to patients without suture fixation to the fascia $(32.8 \%$ vs $15.7 \%, p=0.025)$, regardless of other fixation techniques used. Patients with absorbable tack fixation showed a trend toward less pain when compared with patients with nonabsorbable tack fixation during the entire follow-up period (Fig. 3C). Detailed results of pain perception in the longterm follow-up are shown in Fig. 3 and Table 4.

\section{Discussion}

This propensity score matched prospective observational study was designed to comprehensively assess the outcome after open and laparoscopic incisional hernia repair. In addition to the surgical access, we investigated mesh position 
Table 1 Baseline characteristics of the study population

\begin{tabular}{|c|c|c|c|c|c|c|}
\hline & Crude & & & Matched $^{\mathrm{c}}$ & & \\
\hline & Lap. $(n=154)$ & Open $(n=207)$ & $p$-value & Lap. $(n=150)$ & Open $(n=150)$ & $p$-value \\
\hline Age, years, median (IQR) & $64(54-70)$ & $64(57-71)$ & $0.434^{\mathrm{a}}$ & $64(54-70)$ & $65(57-71)$ & $0.359^{\mathrm{a}}$ \\
\hline Sex, female $(\%) /$ male $(\%)$ & $68(44.2) / 86(55.8)$ & $83(39.4) / 124(60.1)$ & $0.452^{\mathrm{b}}$ & $66(44.0) / 84(56.0)$ & $64(42.7) / 86(57.3)$ & $0.907^{\mathrm{b}}$ \\
\hline BMI, $\mathrm{kg} / \mathrm{m}^{2}$, median (IQR) & $29.2(25.2-33.0)$ & $28.4(25.3-33.0)$ & $0.856^{\mathrm{a}}$ & $29.1(25.2-33.1)$ & $28.4(24.7-32.3)$ & $0.694^{\mathrm{a}}$ \\
\hline ASA score, $n(\%)$ & & & $0.775^{\mathrm{b}}$ & & & $0.915^{\mathrm{b}}$ \\
\hline 1 & $12(7.8)$ & $16(8.5)$ & & $12(8.0)$ & $12(8.0)$ & \\
\hline 2 & $95(61.7)$ & $112(59.6)$ & & $94(62.7)$ & $91(60.7)$ & \\
\hline 3 & $42(27.3)$ & $56(29.8)$ & & $42(28.0)$ & $46(30.7)$ & \\
\hline 4 & $2(1.3)$ & $1(0.5)$ & & $2(1.3)$ & $1(0.7)$ & \\
\hline Missing & $3(1.9)$ & $3(1.6)$ & & - & - & \\
\hline $\begin{array}{l}\text { Hernia size, cran.-caud., cm, } \\
\text { median (IQR) }\end{array}$ & $3.0(2.0-6.0)$ & $5.0(3.0-10.5)$ & $<0.001^{\mathrm{a}}$ & $3.0(2.0-6.0)$ & $5.0(2.0-7.0)$ & $0.068^{\mathrm{a}}$ \\
\hline Hernia localization, $n(\%)$ & & & $0.220^{\mathrm{b}}$ & & & $1.00^{\mathrm{b}}$ \\
\hline Median & $123(79.9)$ & $163(78.7)$ & & $124(82.7)$ & $123(82.0)$ & \\
\hline Lateral & $26(16.9)$ & $42(20.3)$ & & $26(17.3)$ & $27(18.0)$ & \\
\hline Missing & $5(3.2)$ & $2(1.0)$ & & - & - & \\
\hline Site of primary incision, $n(\%)$ & & & $0.018^{\mathrm{b}}$ & & & $0.307^{\mathrm{b}}$ \\
\hline Median laparotomy & $71(46.1)$ & $130(62.8)$ & & $70(46.7)$ & $85(56.7)$ & \\
\hline Transverse laparotomy & $28(18.2)$ & $26(12.6)$ & & $28(18.7)$ & $20(13.3)$ & \\
\hline Laparoscopic access & $33(21.4)$ & $26(12.6)$ & & $32(21.3)$ & $25(16.7)$ & \\
\hline Other & $21(13.6)$ & $24(11.6)$ & & $20(13.3)$ & $20(13.3)$ & \\
\hline Missing & $1(0.6)$ & $1(0.5)$ & & - & - & \\
\hline Smoking, $n(\%)$ & $46(30.1)$ & $47(22.7)$ & $0.144^{\mathrm{b}}$ & $44(29.3)$ & $34(22.7)$ & $0.236^{\mathrm{b}}$ \\
\hline Previous incisional hernia, $n(\%)$ & $29(19.0)$ & $36(17.4)$ & $0.782^{\mathrm{b}}$ & $28(18.7)$ & $30(20.0)$ & $0.884^{\mathrm{b}}$ \\
\hline
\end{tabular}

${ }^{a}$ Mann-Whitney- $U$ test

${ }^{\mathrm{b}}$ Fisher's exact test

${ }^{\mathrm{c}}$ Matched for age, sex, BMI, ASA score, hernia size and localization and primary incision

and fixation technique as factors for long-term postoperative pain.

The study confirms the well-known benefits of laparoscopic compared to open incisional hernia repair as reduced hospital length of stay, less complications and SSI at equal recurrence rates 3 years postoperatively [7]. The prevalence of pain up to 36 months after surgery was not different between the groups. The study demonstrates the advantages of peritoneal suture and tack fixation compared to sutures to the fascia regarding chronic postoperative pain.

Recently introduced endoscopic sublay techniques such as EMILOS [20] and eTEP [21] do not require mesh fixation by sutures or tacks and might therefore combine lower longterm pain levels with known advantages of laparoscopic hernia repair as fewer surgical site infections and shorter length of stay.

A Dutch randomized trial comparing three fixation techniques (absorbable sutures and tacks vs. tacks alone vs. nonabsorbable sutures and tacks) in laparoscopic incisional and ventral hernia repair showed no differences in postoperative pain and quality of life [22]. However, this trial had a very limited follow-up of 3 months only. Similarly, we only found a trend for more pain 3 months after surgery; however, the difference became more evident during the long-term follow-up. An Indian randomized trial comparing transfascial suture versus tack and suture mesh fixation in laparoscopic incisional and ventral hernia repair revealed significantly lower pain levels in the suture group 1-month postoperatively [23]. However, clinical relevance of -0.8 points VAS is questionable and no follow-up beyond 3 months is provided in this trial.

An international multicenter randomized trial comparing tacks alone versus transfascial suture and tack mesh fixation in laparoscopic ventral hernia repair showed less abdominal wall pain in the tacks alone group 3-month postoperatively [24]. Again, no follow-up regarding pain is provided beyond 3-month after surgery. Our study confirms the results of this trial. The absence of mesh fixation to the fascia reduces the postoperative pain even in the long-term after 36 months postoperatively.

A registry-based study from Germany found that pain at one-year follow-up after incisional hernia repair is 
Table 2 Operative technique

\begin{tabular}{|c|c|c|c|}
\hline & Lap & Open & $p$-value \\
\hline Type of mesh, $n(\%)$ & & & $<0.001^{\mathrm{b}}$ \\
\hline Polypropylene & $106(70.7)$ & $126(84.0)$ & \\
\hline Polyester & $43(28.7)$ & $18(12.0)$ & \\
\hline Other & $1(0.7)$ & $2(1.3)$ & \\
\hline No mesh & - & $4(2.7)$ & \\
\hline Mesh position, $n(\%)$ & & & $<0.001^{\mathrm{b}}$ \\
\hline Intraperitoneal & $147(98.0)$ & $40(26.7)$ & \\
\hline Sublay & $3(2.0)$ & $100(66.7)$ & \\
\hline Onlay & - & $5(3.3)$ & \\
\hline Missing data & - & $5(3.3)$ & \\
\hline \multicolumn{4}{|l|}{ Mesh fixation, $n(\%)$} \\
\hline Suture to fascia & $86(57.3)$ & $107(71.3)$ & $0.003^{\mathrm{b}}$ \\
\hline Suture to peritoneum & - & $25(16.7)$ & $<0.001^{\mathrm{b}}$ \\
\hline Tacks & $131(87.3)$ & $17(11.3)$ & $<0.001^{\mathrm{b}}$ \\
\hline Missing data & $11(7.3)$ & $16(10.6)$ & \\
\hline Mesh size, $\mathrm{cm}^{2}$, median (IQR) & $312(225-600)$ & $413(225-600)$ & $0.999^{\mathrm{a}}$ \\
\hline $\begin{array}{l}\text { Duration of the operation, } \\
\text { min. median (IQR) }\end{array}$ & $106(70-135)$ & $140(92-193)$ & $<0.001^{\mathrm{a}}$ \\
\hline
\end{tabular}

${ }^{a}$ Mann-Whitney- $U$ test

${ }^{\mathrm{b}}$ Fisher's exact test associated with female sex [25]. In our study females had significantly more often pain at 3 months postoperatively compared to men ( $52.2 \%$ vs. $33.3 \%, p=0.003)$. However, at 36 months postoperatively the frequency of pain was equal for both sexes.

A recent study from the Netherlands suggests that a structured interview on the phone is sensitive to detect recurrence after incisional hernia repair [26]. However, if the screening questions were answered positively patients were invited for a clinical follow-up in the cited study. A strength of the current study is the entire clinical follow-up, even though it might have reduced the follow-up rate.

The surgical technique differed considerably between the study groups. However, as this study aims to elaborate pain levels in relation to the type of mesh fixation, different operative techniques were permitted.

A limitation of the study is the high dropout rate. Whereas data of close to $85 \%$ of included patients is complete at 12 months follow-up, only $61 \%$ and $65 \%$ of patients presented for the 36 moths follow-up appointment. The study protocol requested a clinical follow-up 36 months after surgery, which might have been the reason for withdrawal from
Fig. 2 Open versus laparoscopic repair. A, B Mesh fixation techniques in open and laparoscopic incisional hernia repair. C Pain perception after open and laparoscopic repair up to 3 years. D Use of absorbable and nonabsorbable tacks in the two groups

\section{A Fixation: Open Repair}

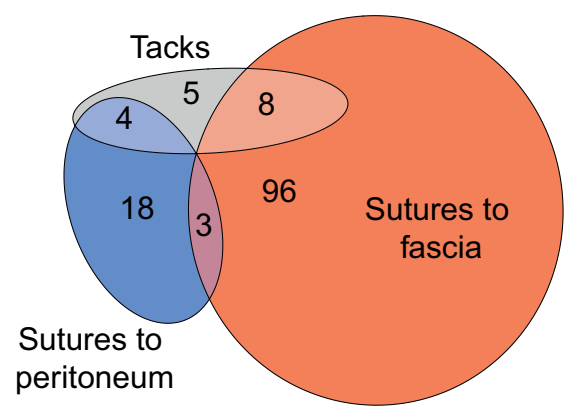

C Pain: Open vs. Lap

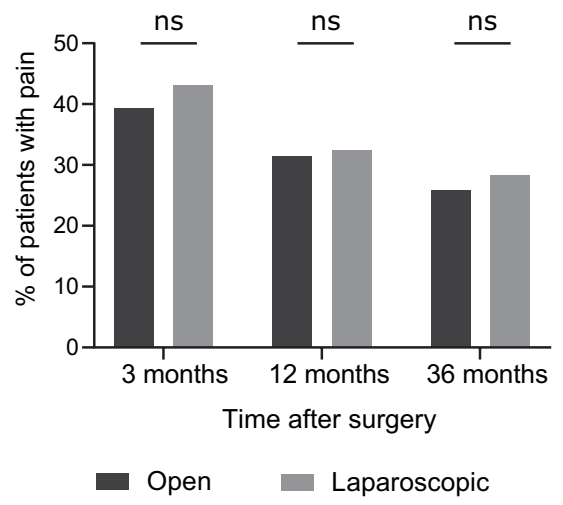

\section{B Fixation: Laparoscopic Repair}

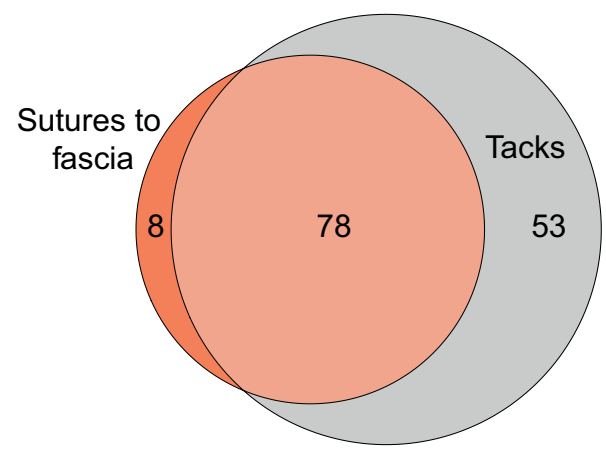

D Use of Tacks

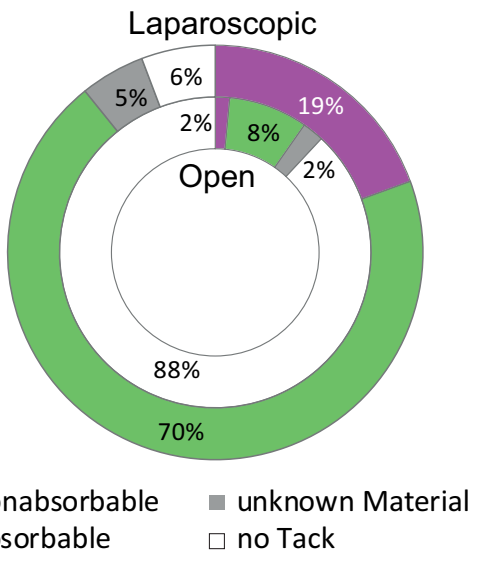


Table 3 Outcomes at hospital discharge

\begin{tabular}{lllr}
\hline & Lap & Open & $p$-value \\
\hline $\begin{array}{l}\text { Postoperative complications, } \\
n(\%)\end{array}$ & $14(9.3)$ & $32(21.3)$ & $0.006^{\mathrm{b}}$ \\
$\begin{array}{l}\text { Dindo-Clavien, } n(\%) \\
\text { Grade I }\end{array}$ & $3(2.0)$ & $8(5.3)$ & \\
Grade II & $2(1.3)$ & $15(10)$ & \\
Grade IIIa & $1(0.7)$ & $2(1.3)$ & \\
Grade IIIb & $5(3.3)$ & $4(2.7)$ & \\
Grade IVa & $3(2.0)$ & $3(2.0)$ & \\
Surgical site infections, $n(\%)$ & & & \\
Superficial & $1(0.7)$ & $8(5.3)$ & $0.036^{\mathrm{b}}$ \\
Deep & - & $1(0.7)$ & $1.000^{\mathrm{b}}$ \\
Organ/space & $3(2.0)$ & - & $0.247^{\mathrm{b}}$ \\
Fistula formation, $n(\%)$ & $1(0.7)$ & - & $1.000^{\mathrm{b}}$ \\
Seroma formation, $n(\%)$ & $1(0.7)$ & $4(2.7)$ & $0.371^{\mathrm{b}}$ \\
Pain level, VAS, median (IQR) & $2(1-3)$ & $2(1-3)$ & $0.104^{\mathrm{a}}$ \\
HLOS, days, median (IQR) & $4(2-5)$ & $5(3-8)$ & $<0.001^{\mathrm{a}}$ \\
Uptake normal daily activities, & $21(14-30)$ & $24(14-42)$ & $0.063^{\mathrm{a}}$ \\
$\quad$ days, median (IQR) & & & \\
\hline
\end{tabular}

VAS Visual Analogue Scale, HLOS hospital length of stay

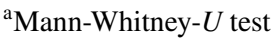

${ }^{b}$ Fisher's exact test

study participation for many participants in this population with $25 \%$ of patients above the age of 70 . Further, over the 3-year period, dropout due to death and loss of contact were responsible for missing data at 36 months of follow-up.

Although propensity score matching is a valid statistical method, this study is limited due to its non-randomized design. Furthermore, the external validity of this study would be increased with a larger patient population.
Table 4 Pain perception and long-term complications

\begin{tabular}{|c|c|c|c|}
\hline & Lap & Open & $p$-value \\
\hline \multicolumn{4}{|l|}{ Preoperative } \\
\hline Pain, $n(\%)$ & $90(62.1)$ & $98(66.2)$ & $0.468^{\mathrm{b}}$ \\
\hline Pain level, VAS, median (IQR) & $4(2-6)$ & $3(2-5)$ & $0.089^{\mathrm{a}}$ \\
\hline Pain killer consumption, $n(\%)$ & $29(19.3)$ & $33(22.0)$ & $0.393^{\mathrm{b}}$ \\
\hline \multicolumn{4}{|l|}{ Follow-up at 3 months } \\
\hline Pain, $n(\%)$ & $59(43.1)$ & $53(39.3)$ & $0.540^{\mathrm{b}}$ \\
\hline Pain level, VAS, median (IQR) & $3.0(2.0-5.0)$ & $3.0(1.0-4.0)$ & $0.138^{\mathrm{a}}$ \\
\hline Pain killer consumption, $n(\%)$ & $15(10.6)$ & $12(8.5)$ & $0.860^{\mathrm{b}}$ \\
\hline Pain localization, $n(\%)$ & & & $0.067^{\mathrm{b}}$ \\
\hline Site of incision & $6(4.0)$ & $17(11.3)$ & \\
\hline Site of fixation & $39(26.0)$ & $25(16.7)$ & \\
\hline Other & $12(8.0)$ & $10(6.7)$ & \\
\hline \multicolumn{4}{|l|}{ Surgical site infections, $n(\%)$} \\
\hline Superficial & $6(4.4)$ & $20(14.8)$ & $0.004^{\mathrm{b}}$ \\
\hline Deep & $2(1.5)$ & $3(2.2)$ & $0.683^{\mathrm{b}}$ \\
\hline Organ/space & $1(0.7)$ & - & $1.000^{\mathrm{b}}$ \\
\hline Fistula formation, $n(\%)$ & $1(0.7)$ & - & $1.000^{\mathrm{b}}$ \\
\hline Seroma formation, $n(\%)$ & $10(7.3)$ & $15(11.1)$ & $0.301^{\mathrm{b}}$ \\
\hline Bulging, $n(\%)$ & $20(14.6)$ & $12(8.9)$ & $0.188^{\mathrm{b}}$ \\
\hline Recurrence, $n(\%)$ & $7(5.1)$ & $1(0.7)$ & $0.066^{\mathrm{b}}$ \\
\hline \multicolumn{4}{|l|}{ Follow-up at 12 months } \\
\hline Pain, $n(\%)$ & $40(32.5)$ & $39(31.5)$ & $0.892^{\mathrm{b}}$ \\
\hline Pain level, VAS, median (IQR) & $3.5(2.0-6.0)$ & $2.0(1.0-4.0)$ & $0.045^{\mathrm{a}}$ \\
\hline Pain killer consumption, $n(\%)$ & $14(11.0)$ & $9(7.2)$ & $0.569^{\mathrm{b}}$ \\
\hline Pain localization, $n(\%)$ & & & $0.999^{\mathrm{b}}$ \\
\hline Site of incision & $8(6.3)$ & $8(6.4)$ & \\
\hline Site of fixation & $18(14.2)$ & $18(14.4)$ & \\
\hline Other & $10(7.9)$ & $11(8.8)$ & \\
\hline Fistula formation, $n(\%)$ & - & $2(1.6)$ & $0.498^{\mathrm{b}}$ \\
\hline Seroma formation, $n(\%)$ & $6(4.8)$ & $15(12.1)$ & $0.066^{\mathrm{b}}$ \\
\hline Recurrence, $n(\%)$ & $15(11.8)$ & $8(6.4)$ & $0.188^{\mathrm{b}}$ \\
\hline \multicolumn{4}{|l|}{ Follow-up at 36 months } \\
\hline Pain, $n(\%)$ & $26(28.3)$ & $23(25.8)$ & $0.740^{\mathrm{b}}$ \\
\hline Pain level, VAS, median (IQR) & $3.0(2.0-4.0)$ & $2.0(1.8-4.0)$ & $0.551^{\mathrm{a}}$ \\
\hline Pain killer consumption, $n(\%)$ & $8(8.7)$ & $4(4.1)$ & $0.544^{\mathrm{b}}$ \\
\hline Pain localization, $n(\%)$ & & & $0.674^{\mathrm{b}}$ \\
\hline Site of incision & $5(5.4)$ & $9(9.3)$ & \\
\hline Site of fixation & $11(12.0)$ & $7(7.2)$ & \\
\hline Other & $7(7.6)$ & $5(5.2)$ & \\
\hline Fistula formation, $n(\%)$ & - & $1(1.1)$ & $0.497^{\mathrm{b}}$ \\
\hline Seroma formation, $n(\%)$ & $2(2.2)$ & $5(5.5)$ & $0.278^{\mathrm{b}}$ \\
\hline Bulging, $n(\%)$ & $23(25.0)$ & $15(16.9)$ & $0.204^{\mathrm{b}}$ \\
\hline Recurrence, $n(\%)$ & $9(9.8)$ & $14(14.4)$ & $0.686^{\mathrm{b}}$ \\
\hline
\end{tabular}

VAS Visual Analogue Scale

${ }^{a}$ Mann-Whitney- $U$ test

${ }^{\mathrm{b}}$ Fisher's exact test 


\section{A Fixation: All Cases}

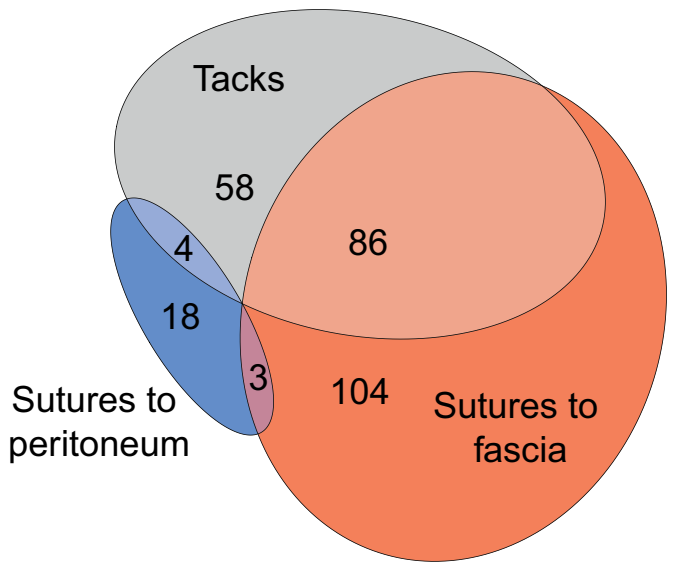

C Pain: Fixation with Tacks

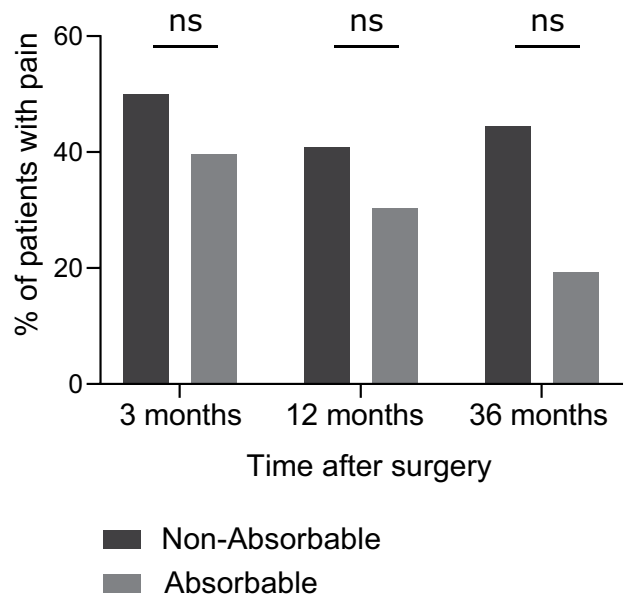

B Pain: Sutures to Fascia

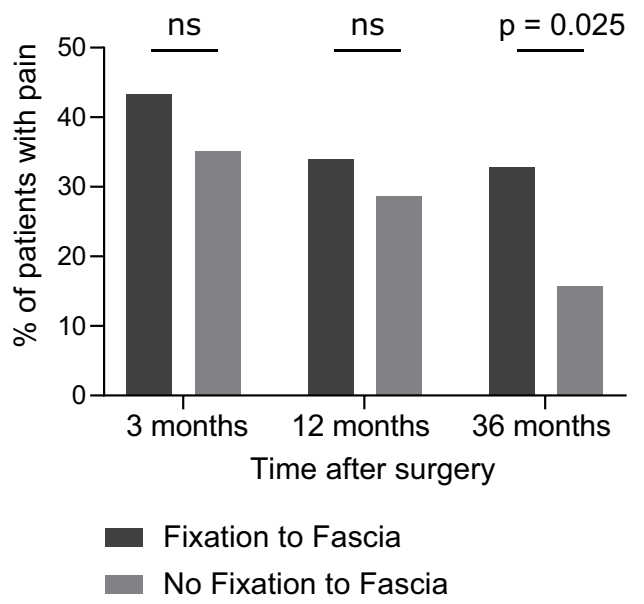

D Pain: Localisation
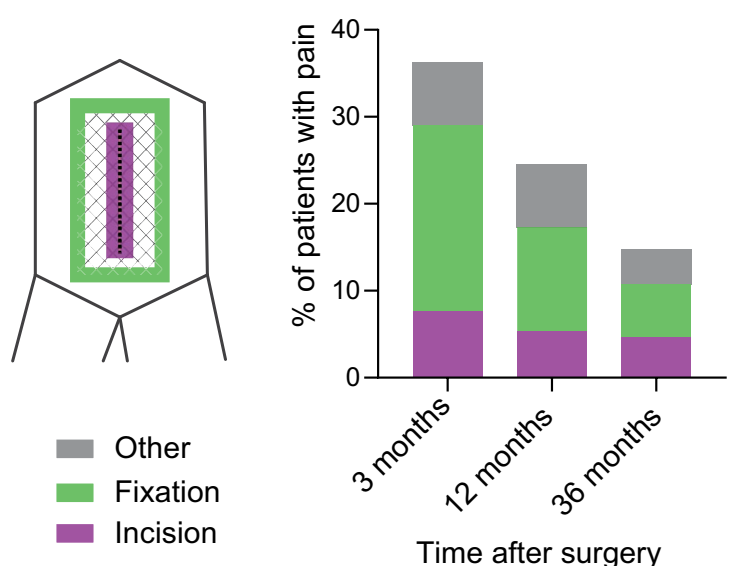

Time after surgery

Fig. 3 Pain levels according to fixation technique. A Mesh fixation for all cases. B Pain with vs. without mesh fixation by sutures to fascia. C Pain after mesh fixation by absorbable vs. non-absorbable tacks. D Site of pain localization after 3, 12 and 36 months

\section{Conclusion}

This propensity score matched prospective study did not show differences in the prevalence of pain at 3,12 and 36 months after laparoscopic versus open incisional hernia repair. Mesh fixation by sutures to fascia was identified to be associated with increased pain 36 months after surgery. Therefore, mesh fixation by sutures to the fascia should be omitted to avoid long-term postoperative pain after hernia repair.

Acknowledgements One of the initiators of this study, Anita Kurmann died on August 7th 2015. The authors acknowledge her humility and great talent and wish that she shall never be forgotten.

Funding Open Access funding provided by Universität Bern.

\section{Compliance with ethical standards}

Disclosures Andreas Kohler, Joël L. Lavanchy, Rahel Gasser, Roland Wyss, Lars Nowak, Andreas Scheiwiller, Peter Hämmerli, Daniel Candinas and Guido Beldi have no conflicts of interest or financial ties to disclose.

Ethical approval All patients included in this study provided written consent. The study was registered at ClinicalTrials.gov (NCT01280370) and approved by the cantonal ethics commission of the canton of Bern, Switzerland (KEK 231/09).

Open Access This article is licensed under a Creative Commons Attribution 4.0 International License, which permits use, sharing, adaptation, distribution and reproduction in any medium or format, as long as you give appropriate credit to the original author(s) and the source, provide a link to the Creative Commons licence, and indicate if changes 
were made. The images or other third party material in this article are included in the article's Creative Commons licence, unless indicated otherwise in a credit line to the material. If material is not included in the article's Creative Commons licence and your intended use is not permitted by statutory regulation or exceeds the permitted use, you will need to obtain permission directly from the copyright holder. To view a copy of this licence, visit http://creativecommons.org/licenses/by/4.0/.

\section{References}

1. Fink C, Baumann P, Wente MN, Knebel P, Bruckner T, Ulrich A, Werner J, Buchler MW, Diener MK (2014) Incisional hernia rate 3 years after midline laparotomy. Br J Surg 101:51-54

2. Basta MN, Kozak GM, Broach RB, Messa CA, Rhemtulla I, DeMatteo RP, Serletti JM, Fischer JP (2019) Can we predict incisional hernia? Development of a surgery-specific decision-support interface. Ann Surg 270:544-553

3. Gillion JF, Sanders D, Miserez M, Muysoms F (2016) The economic burden of incisional ventral hernia repair: a multicentric cost analysis. Hernia 20:819-830

4. Reynolds D, Davenport DL, Korosec RL, Roth JS (2013) Financial implications of ventral hernia repair: a hospital cost analysis. J Gastrointest 17:159-166 (discussion p 166-157)

5. Luijendijk RW, Hop WC, van den Tol MP, de Lange DC, Braaksma MM, Ijzermans JN, Boelhouwer RU, de Vries BC, Salu MK, Wereldsma JC, Bruijninckx CM, Jeekel J (2000) A comparison of suture repair with mesh repair for incisional hernia. New Engl J Med 343:392-398

6. Burger JW, Luijendijk RW, Hop WC, Halm JA, Verdaasdonk EG, Jeekel J (2004) Long-term follow-up of a randomized controlled trial of suture versus mesh repair of incisional hernia. Ann Surg 240:578-583 (discussion 583-575)

7. Lavanchy JL, Buff SE, Kohler A, Candinas D, Beldi G (2019) Long-term results of laparoscopic versus open intraperitoneal onlay mesh incisional hernia repair: a propensity score-matched analysis. Surg Endosc 33:225-233

8. Eker HH, Hansson BM, Buunen M, Janssen IM, Pierik RE, Hop WC, Bonjer HJ, Jeekel J, Lange JF (2013) Laparoscopic vs. open incisional hernia repair: a randomized clinical trial. JAMA Surg 148:259-263

9. Rogmark P, Petersson U, Bringman S, Eklund A, Ezra E, Sevonius D, Smedberg S, Osterberg J, Montgomery A (2013) Short-term outcomes for open and laparoscopic midline incisional hernia repair: a randomized multicenter controlled trial: the ProLOVE (prospective randomized trial on open versus laparoscopic operation of ventral eventrations) trial. Ann Surg 258:37-45

10. Sando A, Rosen MJ, Heniford BT, Bisgaard T (2020) Long-term patient-reported outcomes and quality of the evidence in ventral hernia mesh repair: a systematic review. Hernia 24:695

11. Beldi G, Wagner M, Bruegger LE, Kurmann A, Candinas D (2011) Mesh shrinkage and pain in laparoscopic ventral hernia repair: a randomized clinical trial comparing suture versus tack mesh fixation. Surg Endosc 25:749-755

12. Snyder CW, Graham LA, Vick CC, Gray SH, Finan KR, Hawn MT (2011) Patient satisfaction, chronic pain, and quality of life after elective incisional hernia repair: effects of recurrence and repair technique. Hernia 15:123-129
13. Ben Yehuda A, Nyska A, Szold A (2019) Mesh fixation using novel bio-adhesive coating compared to tack fixation for IPOM hernia repair: in vivo evaluation in a porcine model. Surg Endosc 33:2364-2375

14. Christoffersen MW, Brandt E, Helgstrand F, Westen M, Rosenberg J, Kehlet H, Strandfelt P, Bisgaard T (2015) Recurrence rate after absorbable tack fixation of mesh in laparoscopic incisional hernia repair. Br J Surg 102:541-547

15. Wassenaar EB, Schoenmaeckers EJ, Raymakers JT, Rakic S (2009) Recurrences after laparoscopic repair of ventral and incisional hernia: lessons learned from 505 repairs. Surg Endosc 23:825-832

16. Mangram AJ, Horan TC, Pearson ML, Silver LC, Jarvis WR (1999) Guideline for prevention of surgical site infection, 1999. Hospital infection control practices advisory committee. Infect Control Hosp Epidemiol 20:250-278

17. Dindo D, Demartines N, Clavien PA (2004) Classification of surgical complications: a new proposal with evaluation in a cohort of 6336 patients and results of a survey. Ann Surg 240:205-213

18. Ho DE, Imai K, King G, Stuart EA (2011) MatchIt: nonparametric preprocessing for parametric causal inference. J Stat Softw 42:1-28

19. Larsson J (2019) Eulerr: area-proportional Euler and Venn diagrams with ellipses. R package version 6.0.0. https://cran.r-proje ct.org/package=eulerr. Accessed 3 Apr 2020

20. Schwarz J, Reinpold W, Bittner R (2017) Endoscopic mini/less open sublay technique (EMILOS)-a new technique for ventral hernia repair. Langenbeck's Arch Surg/Deutsche Gesellschaft fur Chirurgie 402:173-180

21. Belyansky I, Daes J, Radu VG, Balasubramanian R, Reza Zahiri H, Weltz AS, Sibia US, Park A, Novitsky Y (2018) A novel approach using the enhanced-view totally extraperitoneal (eTEP) technique for laparoscopic retromuscular hernia repair. Surg Endosc $32: 1525-1532$

22. Wassenaar E, Schoenmaeckers E, Raymakers J, van der Palen J, Rakic S (2010) Mesh-fixation method and pain and quality of life after laparoscopic ventral or incisional hernia repair: a randomized trial of three fixation techniques. Surg Endosc 24:1296-1302

23. Bansal VK, Misra MC, Babu D, Singhal P, Rao K, Sagar R, Kumar S, Rajeshwari S, Rewari V (2012) Comparison of long-term outcome and quality of life after laparoscopic repair of incisional and ventral hernias with suture fixation with and without tacks: a prospective, randomized, controlled study. Surg Endosc 26:3476-3485

24. Muysoms F, Vander Mijnsbrugge G, Pletinckx P, Boldo E, Jacobs I, Michiels M, Ceulemans R (2013) Randomized clinical trial of mesh fixation with "double crown" versus "sutures and tackers" in laparoscopic ventral hernia repair. Hernia 17:603-612

25. Kockerling F, Hoffmann H, Adolf D, Weyhe D, Reinpold W, Koch A, Kirchhoff P (2020) Female sex as independent risk factor for chronic pain following elective incisional hernia repair: registrybased, propensity score-matched comparison. Hernia 24:567-576

26. van Veenendaal N, Poelman MM, van den Heuvel B, Dwars BJ, Schreurs WH, Stoot J, Bonjer HJ (2019) The PINCH-Phone: a new screenings method for recurrent incisional hernias. Surg Endosc 33:2794-2801

Publisher's Note Springer Nature remains neutral with regard to jurisdictional claims in published maps and institutional affiliations. 